\title{
DIREITO ALTERNATIVO COMO INSTRUMENTO DE AFIRMAÇÃO DO DIREITO DE IGUALDADE
}

Rafael Fernando Silva Victor, Rogério José da Silva

Universidade do Oeste Paulista - UNOESTE, Presidente Prudente, SP. E-mail: rafaelfsvictor@gmail.com

\section{RESUMO}

Na busca da efetividade do Direito e a concretização do senso de justiça, surge o Direito Alternativo como forma de afirmar o direito de igualdade. Este artigo fará uma análise nesta vertente e as suas bases, tal como a Teoria Crítica e os Direitos Humanos. Além disso, uma exposição do quanto a justiça é limitada àqueles de baixo poder aquisitivo e o quanto o Direito vigente se encontra estagnado a conceitos limitados que por vezes falha dentro de alguns contextos, necessitando então de um rejuvenescimento e maior acessibilidade a camadas carentes da sociedade. Com isso é proposto meios para mais ação e efetividade no meio jurídico.

Palavras-chave: Direito. Alternativo. Proletariado. Justiça. Igualdade.

\section{ALTERNATIVE LAW AS AN AFFIRMATION INSTRUMENT OF EQUALITY LAW}

\begin{abstract}
In search of the effectiveness of the law and the realization of the sense of justice, arises the Alternative Law as a way of asserting the right to equality. This article will analyze this aspect and its bases, such as Critical Theory and Human Rights. In addition, an exhibition of how justice is limited to those with low purchasing power and how the current law is stagnant the limited concepts that sometimes fail in some contexts, so there's a necessity to revamp and to make more accessible to underprivileged sections of society. It is proposed means for more action and effectiveness in the legal environment.
\end{abstract}

Keywords: Law. Alternative. Proletariat. Justice. Equality. 


\section{INTRODUÇÃO}

Podendo ser chamado de o "Direito do Oprimido", o Direito Alternativo é uma vertente engajada em prol da humanização do Direito vigente, este que é positivado e que já apresenta sinais de desgastes, por vezes se afastando do real objetivo de justiça e sendo apenas um mero instrumento de dominação daqueles que se encontram no poder. Como diria o magistrado Amílton Bueno de Carvalho, um dos mais renomados representantes do Direito Alternativo no Brasil, "o velho está morto, putrefato, o saber transmitido ao jurista (e por ele aplicado) não serve mais ao centro, à esquerda e à direita" ${ }^{1}$ - surge então a necessidade de rejuvenescimento e aproximação real entre o Direito e o pobre, tendo então o Direito Alternativo um comprometimento de resgate daqueles que clamam por igualdade.

Embora tenha uma grande influência política de esquerda, já que esta bebe da fonte marxista, este presente artigo não possui o intuito de ser um texto partidário. O objetivo aqui é proporcionar uma reflexão quanto a concretização dos Direitos Humanos, com enfoque na igualdade, utilizando-se do Direito Alternativo como meio de afirmação de justiça e combate às irregularidades e lacunas do nosso direito vigente.

\section{METODOLOGIA}

Este trabalho é fruto de pesquisas em livros, revistas da área e vivência social, utilizando-se principalmente das obras do magistrado Amílton Bueno de Carvalho como guia para a elaboração do mesmo. O passo inicial foi dado através das revistas do Direito Alternativo, coordenadas por Carvalho e publicadas no início da década de 90 no Brasil. Além disso, foi realizada uma ampla pesquisa no campo de Sociologia Jurídica, tendo como auxílio os conceitos de Boaventura de Sousa Santos e aliada a uma análise da Teoria Crítica do direito como metodologia de produção. 0 "direito achado na rua" também serviu de apoio para a produção deste artigo, assim como a interpretação de conceitos de obras marxistas e dos direitos humanos.

O Direito Alternativo possui como base a Teoria Crítica do Direito, este que vai contra o positivismo puro que enxerga o direito como algo rígido e imutável, acreditando que o direito pode ser um instrumento de libertação do homem oprimido pela sociedade capitalista. Desta forma, concretiza-se as garantias constitucionais e prevalece o princípio de dignidade da pessoa humana. Direito não é sinônimo de lei, mas sim um mecanismo de propagação do bem comum, conciliando a justiça e a igualdade, uma ferramenta de transformação social em busca da emancipação.

Como diz Antônio Carlos Wolkmer:

O comportamento crítico pressupõe uma inter-relação da sociedade com o seu objeto, em que os indivíduos jamais aceitam como naturais os empecilhos que são colocados na sua atividade. O sujeito não procura se conformar com a situação objetiva que lhe é proposta, questionando, avaliando e trabalhando para que o objeto seja transformado. É essa ausência de premissas e a incessante suspeita que caracteriza o caráter dialético do homem que é regido pelo pensamento crítico. (WOLKMER, 2001, p. 15)

A Teoria Crítica do Direito representa uma aceitação da contradição na busca pelo conhecimento, a racionalidade utilizada em formas de dominação através da ciência e das tecnologias é rompida. Ao mesmo tempo que se vincula ao pensamento marxista, recebe influências de Freud, Weber e outros pensadores, formando assim todo um conceito interdisciplinar envolvendo a linguística, psicologia social, psicanálise, ciências sociais e história. A Teoria Crítica representa uma denúncia à exploração econômica do homem pelo homem.

Apoiando-se na obra de Luiz Fernando Coelho, professor de Filosofia do Direito, Volpe Filho

1 CARVALHO, Amílton Bueno de. Apresentação. Revista do Direito Alternativo, ano 1, no 1, São Paulo: Acadêmica, 1991. 
e Scapim destacam as principais características da Teoria Crítica, tais como:

a) o Direito não é sinônimo de Lei, esta é apenas um de seus mecanismos. Direito é justiça, um meio de alcançar a harmonia através da igualdade;

b) o Direito não é uno, existe uma monopolização do Estado que apenas reproduz a ideologia do sistema dominante. Tentam, os críticos, substituir o ineficaz legalismo do estado por outras vias de juridicidade;

c) o Direito não é neutro, o operador jurídico recebe influências de seu meio para analisar as situações. O homem é um conjunto de experiências adquiridas durante a vida, sendo impossível abster-se de seus conceitos e alegar neutralidade;

d) o objeto do Direito é um problema a ser solucionado, ou seja, não é algo para ser apenas descrito de maneira fria. A fonte desta área são os acontecimentos sociais, por esta razão há uma constante mutação que necessita ser acompanhada para que assim resolva seus anseios;

e) o Direito não é racional, como já dito, ele é o produto de um meio social que está em constante mutação e repleto de emoção. Por esta razão não é possível desligar dos operadores jurídicos as suas crenças, emoções, valores e sentimentos inerentes à psique humana;

f) o Direito é um instrumento de mudança social, tendo como objetivo a emancipação da sociedade;

g) o Direito não é dono de uma positividade axiológica do direito, pois não possui uma característica valorativa apenas positiva (justiça, bem comum, igualdade, liberdade, etc.), há também valores negativos na experiência jurídica, como a escravidão, o despotismo e o desprezo pelos direitos humanos. A bondade essencial do direito não passa de artifício retórico para sua imposição ideológica ao consenso da macro-sociedade dominada e seu caráter ético está na dependência de seu uso como instrumento de controle social.

O Direito Alternativo é um movimento teórico-prático formado por operadores jurídicos progressistas, principalmente magistrados, que parte da negação de que as tarefas de interpretação e aplicação do Direito sejam estritamente científicas. No Brasil, o movimento começou a aparecer no final da década de 80 através de magistrados do Rio Grande do Sul poucos anos após o término da ditadura no país. Amílton Bueno de Carvalho possui reservas ao definir o conceito do Direito Alternativo:

[...] atuação comprometida com a busca da vida e da dignidade para todos, e que ambiciona a emancipação popular com a abertura de espaços democráticos, tornando-se instrumento de defesa/libertação contra a dominação imposta (CARVALHO; CARVALHO, 2004, p. 7)

Com o intuito de efetividade de justiça, principalmente àqueles que mais dela necessitam, o Direito Alternativo seria um meio de afirmação dos direitos humanos, garantindo a sua aplicação da liberdade, da igualdade e as exigências para uma vida digna. Desta forma o bem comum tão pregado como finalidade do Estado seria realmente alcançado. Seria os Direitos Humanos uma forma de limitar o poder coercitivo ${ }^{2}$ e o Direito Alternativo uma garantia de aplicação efetiva.

Os Direitos Humanos passaram por um processo evolutivo no decorrer da história, o que fez com que os doutrinadores do direito dividissem o processo em gerações. As três primeiras são remetidas, por vezes, ao lema da Revolução Francesa: Liberdade, Igualdade e Fraternidade, prevendo direitos como à vida, à liberdade, à saúde, ao trabalho, à educação e à paz. A quarta e mais recente geração é dita como "os direitos das minorias". Em busca de garantia de uma igualdade justa, as minorias ganham voz na defesa de seus direitos, tendo a Constituição como base na defesa contra a maioria. Esta geração é fruto da globalização dos direitos fundamentais e

2Se observarmos a evolução da História da humanidade, veremos claramente a transformação do ser humano de súdito do poder (seja o poder real, seja eclesiástico ou até econômico) em cidadão. Isto implicou que fossem definidas regras gerais que limitam, ou, por vezes, até eliminam, o abuso de pode. CUNHA, 2012, p.102. 
possui como foco os direitos à democracia, o direito à informação, o direito ao pluralismo e ampliação das políticas de afirmações das minorias.

$O$ direito à igualdade prevê que todos sejam tratados de maneira igual, sem distinções que não estejam previstas em lei. Mas com isso indagamos: como em uma sociedade tão desigual é possível que todos cumpram as ordens de maneira igual? Na busca de um equilíbrio, tratar igualmente os iguais e desigualmente os desiguais de maneira que se desigualem. Esta isonomia está garantida no caput do artigo 5으 de nossa Constituição, que prevê a igualdade de todos perante a lei. Com este princípio sustenta-se também o direito de todos à justiça.

\section{RESULTADO}

Não pode ser considerado lei algo que não é considerado justo. Ao legislador cabe a criação da norma genérica, enquanto ao juiz cabe expandi-la, não a considerando valida ele possui o livre arbítrio de negá-la. No Direito existe uma falsa noção de neutralidade, porém este caráter "imparcial" tende a privilegiar os fortes, não dando ao oprimido nenhuma opção além da repressão. Não é a aplicação de uma lei que se estabelecerá o que é justo ou injusto, mas sim o seu contexto.

Uma questão frequente no nosso ordenamento jurídico é: os nossos magistrados brasileiros estão aptos para lidar com a massa que está em constante mutação? O que é posto como regra neste momento amanhã pode se tornar obsoleto, além da impossibilidade de um padrão normativo modelador. Por esta razão a autonomia do juiz é necessária, já que ele é a figura viva e vinculada ao mundo em tempo real, apto a captar transformações ao seu redor de modo coerente com o real.

[...] o povo, em sua caminhada histórica, constrói e destrói os direitos que Ihe servem como solução aos seus problemas. A sociedade, por meio de seus sujeitos coletivos - sindicatos, partidos políticos, corporações, setores da igreja, movimentos sociais etc., ao encontrar-se em um contínuo processo de ação, gera suas próprias normas. O Estado não outorga os direitos; é a sociedade que os cria. O Estado se encarrega de canalizar um modo, entre outros, de torná-los efetivos. (CARVALHO; CARVALHO, 2004, p. 11)

\section{DISCUSSÃO}

No Direito vigente existe uma pretensa neutralidade e imparcialidade nas tomadas de decisões que nem sempre convém ao que é chamado de justo, por esta razão há uma necessidade de dinamizar o sistema jurídico com uma atuação assumidamente política, levando-se em consideração o caráter subjetivo existente e que não pode ser ignorado. Os passos a serem tomados são:

a) Individualização de conflitos, já que encaixar um caso em um padrão não garante a efetividade de justiça;

b) Linguagem objetiva e clara, afastando-se de ambiguidades e trazendo a linguagem jurídica para a modernidade;

c) Dar à legislação a aparência de unidade lógica e sistematizada.

Existe uma real necessidade do Judiciário em expor seus conflitos e torná-lo acessível a sociedades pluralistas, submetendo-se a um certo ordenamento legal, mas não de forma repressiva. Esta flexibilidade do Judiciário permite aos intérpretes a renovação dos significados dos textos.

Além da morosidade judicial no Brasil, existem problemas econômicos, sociais e culturais que contribuem com a retenção jurídica e o senso de injusto. A justiça civil é cara para os cidadãos em geral, mas revelam, sobretudo, que a justiça civil é proporcionalmente mais cara para aqueles 
economicamente mais débeis, além da lentidão dos processos, que podem ser facilmente convertidos em um custo econômico adicional proporcionalmente mais gravoso para os cidadãos de menos recursos financeiros.

Outro problema que assola a justiça brasileira é que grande parte dos cidadãos de menores recursos tendem a conhecer menos seus direitos, com isso possuem maior dificuldade em reconhecer um problema que os afeta como sendo problema jurídico. Pessoas de classes desfavorecidas hesitam recorrer aos tribunais mesmo quando reconhecem estar perante um problema legal devido à dificuldade.

O Direito Alternativo clama pelas seguintes medidas para se alcançar um caráter igualitário e justo a todos:

- $\quad$ A administração da justiça envolver mais a participação do cidadão;

- $\quad$ Simplificação dos atos processuais;

- Maior poder ao juiz, levando-se o caráter subjetivo dos casos e não se prendendo a normas genéricas, havendo a possibilidade de adequação;

- Igualdade no acesso à justiça - forma educativa e consciente de direitos àqueles de situação econômica desfavorecida. Seria esta uma forma do direito sair dos tribunais/escritórios e ir para onde o povo está.

A luta democrática pelo direito deve ser no nosso país uma luta pela aplicação do direito vigente tanto quanto uma luta pela mudança do direito. Seria a vertente alternativa uma forma de agilizar e aplicar esta versão dinâmica e igualitária, fazendo com que aqueles que estão à margem da sociedade se integrem ao sistema de maneira efetiva.

\section{CONCLUSÃO}

A luta do Direito Alternativo é a luta pelo reconhecimento de direitos em muitos casos ainda não positivados. A burguesia já é amplamente assistida pelo Direito vigente, tornando este um mero instrumento de dominação. Por isso é necessária a positivação de novos direitos para as camadas populares, desta forma é garantida a efetiva isonomia já prevista constitucionalmente, mas pouco utilizada na prática.

A sociedade é a fonte que dinamiza a gênese, o desenvolvimento e a finalização dos excedentes axiológicos. Estes ficam representados, como parâmetros de orientação universal, pelos princípios gerais do direito. Para que não fiquem no mundo do ideal e do abstrato, deve-se positivá-los, concretizá-los em normas jurídicas. Desta forma passam à vida diária, através da lei, e uma interpretação orientada à sua eficácia plena, se consegue que os ideais humanos de liberdade, de vida em abundância etc., se convertam em realidade. CARVALHO, 2004, p. 10.

A finalidade do Direito Alternativo não é uma questão partidária, mas sim de justiça, trocando-se a dominação pela libertação. É preciso tirar do Direito esta barreira que o separa daqueles que mais necessitam. Isto até pode soar como algo utópico para alguns, mas a revolução nessa área é algo urgente e justo, devolvendo a dignidade daqueles que a perderam por questões gananciosas e exploradoras.

[...] além da concretização, a luta implica em não permitir retrocesso na busca permanente e renovável da utópica vida em abundância para todos. [...] Luta-se, por exemplo, para que normas do Código do Consumidor, direito dos trabalhadores, garantias penais, já incorporados no sistema tenham vida real e não apenas formal. CARVALHO, 2004, p. 60

As bases jurídicas são as relações sociais nas ruas, modificando-se a cada dia. Acompanhar esta mutação não é opcional, mas sim uma obrigação, caso contrário continuaremos em conceitos 
obsoletos e incoerentes com a sociedade atual. Este é o momento dos operadores do direito se movimentarem efetivamente na concretização de um meio justo e harmônico. Como dizia o educador, pedagogo e filósofo brasileiro Paulo Freire: "Não existe imparcialidade. Todos são orientados por uma base ideológica. A questão é: sua base ideológica é inclusiva ou excludente?".

\section{REFERÊNCIAS}

BRASIL. Constituição (1988). Constituição da República Federativa do Brasil. Brasília, DF: Senado, 1988.

CARVALHO, A. B. Magistratura e Direito Alternativo. 3.ed. Rio de Janeiro: Luam Editora, 1991.

CARVALHO, A. B.; CARVALHO, S. (org.). Direito Alternativo brasileiro e pensamento jurídico europeu. Rio de Janeiro: Lumen Juris, 2004.

CUNHA, A. S. Introdução ao Estudo do Direito. São Paulo: Saraiva, 2012.

COELHO, Luiz Fernando. Teoria crítica do direito. 2.ed. Porto Alegre: Sergio Antonio Fabris Editor, 1991.

MARX, Karl. O Capital. Vol. 2. 3.ed. São Paulo: Nova Cultural, 1988.

RODRIGUES, H. W. Ensino Jurídico e Direito Alternativo. São Paulo: Acadêmica, 1993.

SANTOS, Boaventura de Sousa. Introdução à Sociologia da Administração da Justiça. In: FARIA, José Eduardo (org). Direito e Justiça: A Função Social do Judiciário. 3.ed. São Paulo: Ática. 1997. p. 3965.

VOLPE FILHO, C. A; SCAPIM, L. de O. Breves considerações sobre a teoria crítica do Direito. Disponível em: http://www.direitonet.com.br/textos/x/73/55/735/2004. Acesso em 02/06/2016.

WOLKMER, A. C. Pluralismo Jurídico: fundamentos de uma nova cultura do Direito. 3. ed. São Paulo: Alfa-ômega, 2001 